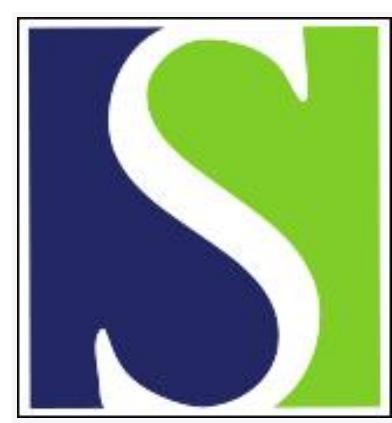

Scand J Work Environ Health 2000;26(4):331-337

https://doi.org/10.5271/sjweh.550

Issue date: Aug 2000

Hormone-dependent cancer and adverse reproductive outcomes in farmers' families - effects of climatic conditions favoring fungal growth in grain

by Kristensen P, Andersen A, Irgens LM

Key terms: breast cancer; climatic conditions; cryptorchidism; endometrial cancer; farmer's family; fungal growth; grain; hormone-dependent cancer; hypospadias; male; mediated spontaneous abortion; mycotoxin; ovarian cancer; reproductive outcome

This article in PubMed: www.ncbi.nlm.nih.gov/pubmed/10994799 


\title{
Hormone-dependent cancer and adverse reproductive outcomes in farmers' families - effects of climatic conditions favoring fungal growth in grain
}

\author{
by Petter Kristensen, MD, ${ }^{\dagger}$ Aage Andersen, ${ }^{2}$ Lorentz M Irgens, $M D^{3}$
}

\begin{abstract}
Kristensen $P$, Andersen A, Irgens LM. Hormone-dependent cancer and adverse reproductive outcomes in farmers' families - effects of climatic conditions favoring fungal growth in grain. Scand J Work Environ Health $2000 ; 26(4): 331-337$

Objectives The impact of grain farming and climate on late-term abortion among female farmers, male genital birth defects among their sons, and hormone-dependent cancer among male and female farmers and their adult children was investigated.

Methods National registers were cross-matched in Norway and 246043 male and female farmers born in 1925 1971 were identified, as were their 264262 children, born in 1952-1980, in agricultural censuses and in the population register. The subjects were followed in the Cancer Register through 1995. Farmers' births, conceived in 1973 - 1991, were identified, and the prevalences of late-term abortion in mothers and hypospadias and cryptorchidism in their sons at birth were examined. Exposure, defined as the combination of grain farming and categories of seasonal or cumulative warnings, was based on data in agricultural censuses and on local, seasonal, field fungal warnings. Estimated adjusted rate ratios or prevalence ratios served as the measures of association.

Results Categories of high exposure were associated with reproductive outcomes and cancer among female farmers, the strongest occurring for late-term abortion (ratio $2.6,95 \%$ confidence interval (95\% CI) $1.6-4.3$ ). Exposure associations for ovarian and breast cancer, and male genital defects, were more moderate. Endometrial cancer was associated with grain farming (ratio 2.0, 95\% CI 1.4-2.8) across all levels of fungal warnings. Exposure associations for cancer were strongest for premenopausal, parous women. Exposure was not associated with cancer among male farmers or children.

Conclusions Climatic conditions favoring fungal growth in grain were associated with hormone-dependent adverse outcomes among female farmers; the results are consistent with hormonal effects of inhaled mycotoxins during pregnancy.
\end{abstract}

Key terms breast cancer, cryptorchidism, endometrial cancer, hypospadias, mycotoxins, ovarian cancer, spontaneous abortion.

The hypothesis that exposure to endocrine-disrupting xenobiotics and natural toxins causes adverse health effects as a result of hormone modulation has attracted wide attention $(1-3)$. Male reproductive performance, genital birth defects, testicular cancer, prostate cancer, and breast cancer have been main concerns. Except for conflicting results in breast cancer studies (4-6) the epidemiologic evidence is scarce. Ovarian and endometrial cancer have rarely been considered in this respect ( 7 , 8 ). Occurrences of several of these outcomes have increased; therefore man-made chemicals have been suspected culprits. Several natural toxins also have endocrine-modulating properties $(2,3)$, and the mycotoxin zearalenone produced by Fusarium field fungi has received attention $(2,3,9)$. Zearalenone and other mycotoxins have been identified in grain, and are recognized problems in grain harvests under difficult climatic conditions (10-12).

We have earlier studied perinatal outcomes and cancer among Norwegian farmer families (13-16) and found that very preterm delivery was associated with poor regional harvest conditions on grain farms (13). In our present study, we have investigated associations between meteorological conditions on grain farms, and several hormone-dependent reproductive outcomes and cancers in the earlier established family cohort. We used

1 National Institute of Occupational Health, Oslo, Norway.

2 The Cancer Registry of Norway, Institute of Epidemiological Cancer Research, Oslo, Norway.

3 Medical Birth Registry of Norway, University of Bergen, Bergen, Norway.

Reprint requests to: Dr Petter Kristensen, National Institute of Occupational Health, POB 8149 Dep, N—0033 Oslo, Norway. [E-mail: petter.kristensen@stami.no] 
fungal warnings based on local climate data in the growing seasons and updated the cancer data by extending follow-up through 1995. The study hypothesis was that conditions favoring fungal growth and mycotoxin formation constitute a risk for hormone-dependent adverse outcomes

\section{Material and methods}

Statistics Norway conducted 3 agricultural and 2 horticultural censuses during 1969-1989, and these censuses resulted in computerized data files. By means of the personal identification number assigned to all Norwegian residents, we identified farm holders, born in 1925 1971 , in the censuses, as well as spouses, born in 19251971, and their children, born in 1952-1991, in a linkage with the Central Population Register. These farm holders, spouses, and children were followed for incident cancer in the Cancer Register. We linked the file of farmers and spouses to the Medical Birth Register of Norway to identify their births. The establishment of the cohort and linking procedures have been described in more detail elsewhere $(13-16)$. On the basis of these linking procedures we established 6 analysis files: a file of mothers (late-term abortion study), their newborn sons (hypospadias and cryptorchidism), female farmers (cancer), male farmers (cancer), farmers' daughters (cancer), and farmers' sons (cancer).

\section{Exposure}

We linked information about grain farming provided in the agricultural and horticultural censuses to all the

Table 1. Study populations at risk and the distribution of grain farming in the Norwegian farming population.

\begin{tabular}{|c|c|c|c|c|}
\hline Study populations & $\begin{array}{c}\text { Study } \\
\text { outcome }\end{array}$ & Total & $\begin{array}{l}\text { Non- } \\
\text { grain }\end{array}$ & Grain \\
\hline $\begin{array}{l}\text { Female farmers with } \\
\text { pregnancies conceived } \\
\text { during June 1973-May } 1991\end{array}$ & $\begin{array}{l}\text { Late- } \\
\text { term } \\
\text { abortion }\end{array}$ & 56720 & 41383 & 15337 \\
\hline 0 seasonal late blight warnings ${ }^{a}$ & & & 24366 & 7176 \\
\hline 1 seasonal late blight warnings & & & 11050 & 4922 \\
\hline 2 seasonal late blight warnings ${ }^{a}$ & & & 3390 & 1855 \\
\hline$\geq 3$ seasonal late blight warnings ${ }^{a}$ & & & 2577 & 1384 \\
\hline $\begin{array}{l}\text { Sons, conceived during } \\
\text { June } 1973-\text { May } 1991\end{array}$ & $\begin{array}{l}\text { Birth } \\
\text { defects }\end{array}$ & 52062 & 39846 & 12216 \\
\hline Female farmers born in $1925-1971$ & 1 Cancer 1 & 109752 & 72026 & 37726 \\
\hline 0 seasons with $\geq 2$ warnings & & & 18959 & 11616 \\
\hline $1-2$ seasons with $\geq 2$ warnings ${ }^{b}$ & & & 20123 & 6850 \\
\hline $3-5$ seasons with $\geq 2$ warnings ${ }^{b}$ & & & 22760 & 9744 \\
\hline$\geq 6$ seasons with $\geq 2$ warnings ${ }^{b}$ & & & 10184 & 9516 \\
\hline Male farmers born in $1925-197 \dagger$ & Cancer 1 & 136291 & 89006 & 47285 \\
\hline Daughters born in $1952-1980$ & Cancer 1 & 128578 & 93611 & 34967 \\
\hline Sons born in $1952-1980$ & Cancer 1 & 135684 & 98897 & 36787 \\
\hline
\end{tabular}

a In season of first conception.

b During 1973-1990. records. For reproductive outcomes (late-term abortion, birth defects) and offspring cancer, categorization was dependent on data in the census closest in time to the conception or birth, respectively; about $25 \%$ were categorized to have grain farming parents. In the study of cancer among male and female farmers, approximately $35 \%$ of the subjects were classified as grain farmers on the criterion that grain was cultivated in any census year.

As a tool against field fungus (late blight) growth in potato, the Norwegian Meteorological Institute and the Norwegian Crop Research Institute have, since 1958, provided daily warnings during the growing season (midJune to mid-September) (17). Warnings are based on observations from local weather stations. The criteria for a warning apply for 2 consecutive days, and they remained unchanged until the $1990 \mathrm{~s}$, being a minimum temperature of $\geq 10^{\circ} \mathrm{C}$, a maximum temperature of between 17 and $24^{\circ} \mathrm{C}$, a relative humidity of $\geq 75 \%$, and precipitation. We allocated computerized warning data from 46 stations during 1973 - 1990 to all the study farms according to their location.

\section{Reproductive outcomes}

The Medical Birth Register of Norway, comprising since 1967 birth notifications for all deliveries from $16 \mathrm{com}$ pleted weeks of gestation, provided data on the reproductive outcomes under study, namely, late-term abortion defined as stillbirth during 16-27 completed weeks of gestation and genital birth defects (hypospadias and cryptorchidism) among the boys.

We identified 101192 births with exposure information (conceptions between June 1973 and May 1991, see the Analysis section). On the basis of these births, the following 2 analysis files were prepared: 56720 women with singleton pregnancies (late-term abortion investigation) and 52062 newborn boys (investigation of hypospadias and cryptorchidism recognized at birth; table 1).

\section{Cancer}

Case reporting to The Cancer Registry of Norway includes both clinical and pathological data and has been mandatory since 1952. In the linkage and follow-up we identified incident cases of breast adenocarcinoma (female farmers, daughters), ovarian adenocarcinoma (female farmers, daughters), endometrial adenocarcinoma (female farmers), testicular cancer (male farmers, sons) and prostate cancer (male farmers).

The follow-up of cancer among the male and female farmers born in 1925-1971 started 1 January in the year of the first agricultural census participation, but not before the attained age of 20 years. Children born in 19521980 were followed from the date of their 15 th birthday. Follow-up continued through 1995 or to the time of death or emigration, whichever occurred first. Thus the oldest farmers were 70 years old and the oldest children were 
43 years old at the end of the follow-up. In an attempt to avoid bias from a selective loss of unidentified dead children or spouses in the population register $(14,15)$, the children were not followed before 1971 and spouses not before 1986 .

The 4 populations contributing person-years were 109752 female farmers ( 1024344 person-years), 136291 male farmers ( 2023903 person-years), 128578 daughters (1 716867 person-years), and 135684 sons (1 810263 person-years; table 1).

\section{Analysis}

The analyses were performed with the Epicure software package (18). We computed prevalences for those at risk of reproductive outcomes (per 1000 mothers for late-term abortion and per 10000 male offspring for birth defects). Cancer incidence rates were calculated per 100000 person-year's at risk.

The exposure under study was the combination of grain farming and late blight warnings. We constructed time-specific and cumulative variables on the basis of the warning counts allocated to each farm during 18 seasons. For reproductive outcomes, the warning count in a specific season was assigned to pregnancies or births conceived between June in the same season and May of the next year. Thus conceptions between June 1973 and May 1991 were studied. Time of conception was based on information on the first day of the last menstrual period in the Medical Birth Register. For cancer, we used the cumulative number of years with more than 1 warning, divided into quartiles according to the distribution among grain farmers $(0,1-2,3-5$ and $\geq 6$ years $)$. Examples of the distributions of season-specific warnings and the number of years with more than 1 warning are provided in table 1.

We used ratio estimates as measures of association, prevalence ratios for reproductive outcomes, and rate ratios for cancer. The ratios were computed in contingency tables that were stratified by potential confounders, and Poisson regression models controlled for these variables.

An initial analysis showed that maternal age $(<20$, $20-34, \geq 35$ years) and calendar year (5-year intervals) were associated with late-term abortion and birth defects. Age (5-year intervals) and calendar year (5-year intervals) were associated with all the cancers under study; in addition, parity $(0,1-2,3, \geq 4)$ influenced female cancers. Hence, we deemed adjustment relevant and controlled for these variables in the analyses. Reproductive patterns, which could influence risks of adverse reproductive outcomes and reproductive cancer, vary in different parts of Norway. Furthermore, both grain farming and late blight warnings were dependent on farm location and pesticide application. Therefore we adjusted for geographic region (5 regions) and an indicator of pesticide use. Pesticide use was defined as having spent money on pesticides (1969 census) or having pesticide spraying equipment on the farm (1979 census). Approximately $40 \%$ of the subjects in the different analysis files used pesticides; about 4\% did not participate in the 1969 or 1979 census.

We also performed analyses in separate strata of maternal age and parity. Female reproductive cancer risk is dependent on childbirth and hormonal status (6-8); therefore we had a specific interest of investigating the heterogeneity of exposure effects across categories of parity and age in relation to menopause.

\section{Results}

\section{Reproductive outcomes}

A total of 395 women ( 7.0 per 1000) experienced lateterm abortion. The prevalence of the grain farmers was moderately higher than that of the nongrain farmers, 7.8 and 6.7, respectively. Grain farmers had increasing prevalence ratios of late-term abortion in association with seasonal warnings [ $\geq 3$ warnings, ratio $2.6,95 \%$ confidence interval $(95 \% \mathrm{CI}) 1.6-4.3$ ] (table 2 ).

The prevalence ratio for hypospadias was increased in the category of grain farming with $\geq 2$ warnings in the season of conception (table 2). The prevalence of

Table 2. Associations between the combination of grain farming and number of season-specific late blight warnings and selected reproductive outcomes for the 56720 Norwegian female farmers who conceived between June 1973 and May 1991 and their 52062 sons at birth. $(95 \% \mathrm{Cl}=95 \%$ confidence interval)

\begin{tabular}{|c|c|c|c|c|}
\hline Exposure category & $\begin{array}{l}\text { Cases } \\
(\mathrm{N})\end{array}$ & Prevalence $^{\mathrm{a}}$ & $\begin{array}{l}\text { Prevalence } \\
\text { ratio }\end{array}$ & $95 \% \mathrm{Cl}$ \\
\hline \multicolumn{5}{|l|}{ Late-term abortion } \\
\hline Nongraine & 276 & 6.7 & 1.0 & \\
\hline \multicolumn{5}{|l|}{ Grain } \\
\hline 0 warnings & 51 & 7.1 & 1.4 & $1.0-1.9$ \\
\hline 1 warning & 31 & 6.3 & 1.2 & $0.8-1.8$ \\
\hline 2 warnings & 19 & 10.2 & 1.8 & $1.1-2.9$ \\
\hline$\geq 3$ warnings & 18 & 13.0 & 2.6 & $1.6-4.5$ \\
\hline \multicolumn{5}{|l|}{ Hypospadias } \\
\hline Nongrainc & 103 & 25.8 & 1.0 & \\
\hline \multicolumn{5}{|l|}{ Grain } \\
\hline 0 warnings & 19 & 31.2 & 1.0 & $0.5-1.7$ \\
\hline 1 warning & 8 & 22.3 & 0.8 & $0.4-1.7$ \\
\hline$\geq 2$ warnings & 13 & 50.7 & 1.8 & $0.9-3.4$ \\
\hline \multicolumn{5}{|l|}{ Cryptorchidism } \\
\hline Nongrainc & 88 & 22.1 & 1.0 & \\
\hline \multicolumn{5}{|l|}{ Grain } \\
\hline 0 warnings & 6 & 9.9 & 0.3 & $0.1-0.7$ \\
\hline 1 warning & 11 & 30.8 & 0.9 & $0.5-1.8$ \\
\hline$\geq 2$ warnings & 11 & 43.0 & 1.2 & $0.6-2.4$ \\
\hline
\end{tabular}

ate-term abortion per 1000 women; bith defects per 10000 male births.

- Adjusted for maternal age, calendar year, region and pesticide use.

c Reference group. 
Table 3. Associations between the combined exposure of grain farming and number of years with $\geq 2$ late blight warnings and hormone-dependent cancer in the Norwegian farming population. (95\% $\mathrm{Cl}=95 \%$ confidence interval)

\begin{tabular}{|c|c|c|c|c|}
\hline Exposure category & $\begin{array}{l}\text { Cases } \\
(\mathrm{N})\end{array}$ & $\begin{array}{l}\text { Incidence } \\
\text { rate }^{\mathrm{a}}\end{array}$ & $\begin{array}{l}\text { Rate } \\
\text { ratio }\end{array}$ & $95 \% \mathrm{Cl}$ \\
\hline \multicolumn{5}{|c|}{ Endometrial adenocarcinoma, female farmers } \\
\hline Nongrain ${ }^{\mathrm{c}}$ & 125 & 18.4 & 1.0 & $\cdot$ \\
\hline \multicolumn{5}{|l|}{ Grain } \\
\hline 0 warning years & 31 & 29.1 & 1.8 & $1.1-2.9$ \\
\hline $1-2$ warning years & 13 & 20.5 & 1.3 & $0.7-2.5$ \\
\hline $3-5$ warning years & 35 & 39.1 & 2.6 & $1.7-4.1$ \\
\hline$\geq 6$ warning years & 24 & 27.6 & 1.9 & $1.1-3.3$ \\
\hline \multicolumn{5}{|c|}{ Ovarian adenocarcinoma, female farmers } \\
\hline Nongrain ${ }^{c}$ & 171 & 25.2 & 1.0 & . \\
\hline \multicolumn{5}{|l|}{ Grain } \\
\hline 0 warning years & 30 & 28.2 & 1.1 & $0.7-1.7$ \\
\hline $1-2$ warning years & 23 & 36.3 & 1.4 & $0.9-2.4$ \\
\hline $3-5$ warning years & 31 & 34.7 & 1.5 & $1.0-2.3$ \\
\hline$\geq 6$ warning years & 26 & 29.9 & 1.4 & $0.8-2.2$ \\
\hline \multicolumn{5}{|c|}{ Breast adenocarcinoma, female farmers } \\
\hline Nongrain" & 635 & 93.6 & 1.0 & . \\
\hline \multicolumn{5}{|l|}{ Grain } \\
\hline 0 warning years & 79 & 74.2 & 1.0 & $0.7-1.3$ \\
\hline $1-2$ warning years & 64 & 100.9 & 1.3 & $1.0-1.8$ \\
\hline $3-5$ warning years & 72 & 80.5 & 1.2 & $0.9-1.5$ \\
\hline$\geq 6$ warning years & 71 & 81.7 & 1.3 & $1.0-1.7$ \\
\hline \multicolumn{5}{|c|}{ Testicular cancer, farmers } \\
\hline Nongrain ${ }^{\circ}$ & 114 & 8.9 & 1.0 & . \\
\hline \multicolumn{5}{|l|}{ Grain } \\
\hline 0 warning years & 20 & 8.9 & 1.0 & $0.6-1.8$ \\
\hline $1-2$ warning years & 13 & 9.9 & 1.0 & $0.5-2.0$ \\
\hline $3-5$ warning years & 14 & 7.3 & 0.7 & $0.4-1.4$ \\
\hline$\geq 6$ warning years & 23 & 12.1 & 1.2 & $0.7-2.0$ \\
\hline \multicolumn{5}{|l|}{ Prostate cancer, farmers } \\
\hline Nongrain ${ }^{c}$ & 499 & 38.8 & 1.0 & . \\
\hline \multicolumn{5}{|l|}{ Grain } \\
\hline 0 warning years & 72 & 32.0 & 1.0 & $0.7-1.3$ \\
\hline $1-2$ warning years & 50 & 38.3 & 1.2 & $0.9-1.6$ \\
\hline $3-5$ warning years & 49 & 25.5 & 0.8 & $0.6-1.0$ \\
\hline$\geq 6$ warning years & 51 & 26.9 & 0.8 & $0.6-1.2$ \\
\hline \multicolumn{5}{|c|}{ Ovarian adenocarcinoma, daughters } \\
\hline Nongrain $^{\circ}$ & 55 & 4.4 & 1.0 & . \\
\hline \multicolumn{5}{|l|}{ Grain } \\
\hline 0 warning years & 5 & 3.5 & 0.5 & $0.2-1.5$ \\
\hline $1-2$ warning years & 0 & 0.0 & - & . \\
\hline $3-5$ warning years & 0 & 0.0 & - & \\
\hline$\geq 6$ warning years & 5 & 3.9 & 0.7 & $0.2-1.9$ \\
\hline \multicolumn{5}{|c|}{ Breast adenocarcinoma, daughters } \\
\hline Nongrainc & 55 & 4.4 & 1.0 & . \\
\hline \multicolumn{5}{|l|}{ Grain } \\
\hline 0 warning years & 1 & 0.7 & 0.1 & $0.0-1.1$ \\
\hline $1-2$ warning years & 4 & 5.1 & 1.2 & $0.4-3.6$ \\
\hline $3-5$ warning years & 3 & 2.5 & 0.6 & $0.2-2.1$ \\
\hline$\geq 6$ warning years & 3 & 2.3 & 0.5 & $0.1-1.8$ \\
\hline \multicolumn{5}{|l|}{ Testicular cancer, sons } \\
\hline Nongrain ${ }^{\circ}$ & 193 & 14.7 & 1.0 & . \\
\hline \multicolumn{5}{|l|}{ Grain } \\
\hline 0 warning years & 15 & 10.0 & 0.8 & $0.4-1.4$ \\
\hline $1-2$ warning years & 15 & 17.6 & 1.3 & $0.7-2.3$ \\
\hline $3-5$ warning years & 11 & 8.5 & 0.6 & $0.3-1.1$ \\
\hline$\geq 6$ warning years & 22 & 16.3 & 1.2 & $0.7-2.1$ \\
\hline
\end{tabular}

a Incidence density (cases per 100000 person-years).

b Female farmers: adjusted for age, calendar year, parity, region, and pesticide use; male farmers, daughters and sons: adjusted for age, calendar year, region, and pesticide use.

c Reference group.
Table 4. Associations between endometrial and ovarian adenocarcinoma among Norwegian female farmers and the combined exposure of grain farming and number of years with $\geq 2$ late blight warnings, by parity and age.

\begin{tabular}{|c|c|c|c|c|}
\hline Exposure category & $\begin{array}{l}\text { Cases } \\
\text { (N) }\end{array}$ & $\begin{array}{l}\text { Incidence } \\
\text { rate }^{\mathrm{a}}\end{array}$ & $\begin{array}{l}\text { Rate } \\
\text { ratio }\end{array}$ & $95 \% \mathrm{Cl}$ \\
\hline \multicolumn{5}{|c|}{ Endometrial adenocarcinoma, parous farmers } \\
\hline Nongrainc & 91 & 16.0 & 1.0 & . \\
\hline \multicolumn{5}{|l|}{ Grain } \\
\hline $0-2$ warning years & 32 & 22.7 & 1.6 & $1.0-2.7$ \\
\hline$\geq 3$ warning years & 50 & 32.3 & 2.6 & $1.5-4.1$ \\
\hline \multicolumn{5}{|c|}{ Endometrial adenocarcinoma, nulliparous farmers } \\
\hline Nongrain & 34 & 31.4 & 1.0 & . \\
\hline \multicolumn{5}{|l|}{ Grain } \\
\hline $0-2$ warning years & 12 & 41.2 & 1.7 & $0.7-3.9$ \\
\hline$\geq 3$ warning years & 9 & 41.4 & 1.5 & $0.6-3.8$ \\
\hline \multicolumn{5}{|c|}{ Ovarian adenocarcinoma, parous farmers, attained age $20-49$ years } \\
\hline Nongrainc & 47 & 14.3 & 1.0 & . \\
\hline \multicolumn{5}{|l|}{ Grain } \\
\hline $0-2$ warning years & 18 & 20.7 & 1.6 & $0.8-3.2$ \\
\hline$\geq 3$ warning years & 27 & 27.6 & 2.5 & $1.3-4.7$ \\
\hline \multicolumn{5}{|c|}{ Ovarian adenocarcinoma, nulliparous farmers or attained age $\geq 50$ years } \\
\hline Nongrain ${ }^{6}$ & 124 & 35.4 & 1.0 & . \\
\hline \multicolumn{5}{|l|}{ Grain } \\
\hline $0-2$ warning years & 35 & 42.3 & 1.1 & $0.7-1.7$ \\
\hline$\geq 3$ warning years & 30 & 38.2 & 1.0 & $0.6-1.7$ \\
\hline \multicolumn{5}{|c|}{ Breast adenocarcinoma, parous farmers, attained age $20-49$ years } \\
\hline Nongrain ${ }^{\circ}$ & 207 & 63.2 & 1.0 & \\
\hline \multicolumn{5}{|l|}{ Grain } \\
\hline $0-2$ warning years & 43 & 49.4 & 1.0 & $0.7-1.5$ \\
\hline$\geq 3$ warning years & 62 & 63.5 & 1.6 & $1.1-2.3$ \\
\hline \multicolumn{5}{|c|}{ Breast adenocarcinoma, nulliparous farmers or attained age $\geq 50$ years } \\
\hline Nongrain & 428 & 122.1 & 1.0 & . \\
\hline \multicolumn{5}{|l|}{ Grain } \\
\hline $0-2$ warning years & 100 & 120.8 & 1.2 & $0.9-1.5$ \\
\hline$\geq 3$ warning years & 81 & 103.0 & 1.0 & $0.8-1.4$ \\
\hline
\end{tabular}

a Incidence density (cases per 100000 person-years).

b Adjusted for age, calendar year, parity, region and pesticide use, except for endometrial cancer analysis in nulliparous farmers (adjusted for age, calendar year, region, and pesticide use).

- Reference group.

cryptorchidism was not increased for the grain farmers' sons, but within the grain farming group it was highly dependent on seasonal warning counts, being only 9.9 per 10000 in the zero warning category and 43.0 in the $\geq 2$ warning category.

\section{Cancer}

Exposure was associated with hormone-dependent cancers among the female farmers. Endometrial adenocarcinoma was associated with grain farming (adjusted rate ratio $2.0,95 \%$ CI $1.4-2.8$ ) across all the warning strata; the highest ratio was found in the 3rd warning quartile (table 3). Ovarian adenocarcinoma showed a moderate association with grain farming (adjusted rate ratio 1.3, 95\% CI 1.0-1.8), with moderately increased associations (ratios 1.4-1.5) in all the grain farming strata with years of warnings (table 3 ). Breast adenocarcinoma was 
slightly associated with grain farming (adjusted rate ratio $1.2,95 \% \mathrm{CI} 1.0-1.4$ ). The crude rates for breast adenocarcinoma were low in most of the grain-warning strata in comparison with those of the nongrain farmers (table 3). However, pesticide use was a confounder, and the adjusted rate ratios were slightly increased (ratios $1.2-1.3)$.

Contrary to the results for female farmers, we found no positive exposure associations with testicular and prostate cancer among the male farmers, breast adenocarcinoma and ovarian adenocarcinoma among the daughters, or testicular cancer among the sons (table 3).

The exposure associations for female farmers were dependent on parity and age, being stronger for parous women during premenopausal age (table 4). For endometrial adenocarcinoma, the association was stronger for parous than for nulliparous women. The rate ratio for parous grain farmers with $\geq 3$ warning years was $2.6(95 \%$ 1.5-4.1); the incidence rate in this stratum was in fact higher than for nulliparous nongrain farmers. An even stronger exposure association was found for parous women aged $20-49$ years, but the estimate was based on few cases (data not shown).

For ovarian adenocarcinoma, the exposure association was almost entirely restricted to parous women who were followed before 50 years of age $(\geq 3$ warning years, rate ratio $2.5,95 \% \mathrm{CI} 1.3-4.7$ ) (table 4 ). The same association was also found for breast adenocarcinoma $(\geq 3$ warning years, rate ratio $1.6,95 \% \mathrm{CI} 1.1-2.3$ ), but the crude rate was not increased in a comparison with the nongrain farmers.

\section{Discussion}

This study provides evidence that weather conditions in grain farming are associated with late-term abortion and ovarian adenocarcinoma among female farmers. A more moderate association was found for breast adenocarcinoma. Endometrial cancer was associated with grain farming across all the strata of fungal warnings. Exposure associations were stronger for cancer among premenopausal parous women. The support of a similar exposure association for genital birth defects among male offspring was more limited. There was no indication of exposure associations with study cancers among the male farmers and their sons and daughters. The late-term abortion result is in accord with earlier findings in the same population, for which a cruder regional assessment of harvest conditions was applied (13). We are not aware of other epidemiologic studies supporting these results, with the exception of an increased incidence of ovarian cancer among premenopausal paper pulp workers who were potentially exposed to fungi (19).
In addressing these novel findings, we must first consider noncausal explanations. Complete participation was made possible by the unique identification number assigned to all national residents, but our study shares the limitations that have been found for most register-based studies with respect to exposure data quality.

The grain farming variable was based on cross-sectional census data. However, the resulting misclassification was likely to be limited since nearly $90 \%$ of those who cultivated grain according to 1 census reported grain farming in all the censuses. Fusarium and Fusarium toxins are widespread in Norwegian grain (10), and the relation between climate and toxin levels in grain (12) suggests that our warning variables were useful indicators of fungal growth and mycotoxin formation. Furthermore, Fusarium growth and mycotoxin formation have been demonstrated in storage silos under realistic conditions (20). The climate in Norway requires that grain be stored and dried indoors from the harvest in August-October until December-January. Grain handling during harvest, storage, drying and mill delivery can involve dust inhalation (21). However, our data on exposure opportunity do not indicate actual levels or the exact timing of exposure. The cumulative warning variable was a particular problem, reflecting an average of over 18 years. We were not able to investigate effects of time-specific prenatal exposure on cancer in the sons and daughters because the study cancers were few among subjects born in 1973 1991. The exposure misclassification in our study was likely to be independent of outcome; therefore the effect would be conservative, attenuating true associations and dose-response gradients.

The results may have been confounded by determinants not fully accounted for. For female farmers, we lacked data on some reproductive parameters (age at menarche, first birth and menopause, interpregnancy intervals, breast feeding), obesity, diet, and the use of oral contraceptives. Compared with the general population, the farming population in Norway is rather conservative in life-style and reproductive patterns, and there are no indications of distinct differences within this population concerning these potential confounders. Therefore we do not consider them to be likely explanations of the stronger exposure associations observed, but such factors could possibly explain weak associations, for example, the breast cancer results.

Pesticide use is a particular concern that could have had a complex influence on our results. Fungicides, herbicides, and growth regulators, of which some have weak endocrine-disrupting properties $(2,3)$, are more likely to be applied under climatic conditions that favor fungal growth. At the same time, the use of pesticides alters fungal and mycotoxin formation. Our pesticide use indicator was correlated with fungal warnings, and it was negatively associated with late-term abortion and the study 
cancers among female farmers and positively associated with cryptorchidism. Accordingly, pesticide-use adjustment strengthened the exposure associations for the cancers, in particular breast adenocarcinoma, and weakened the exposure associations for cryptorchidism. One speculative interpretation would be that pesticides counteract the exposure effects on cancer and are truly related to male genital birth defects in accordance with earlier results from our study population (16) and also results from other studies $(22,23)$.

Given that the reported exposure effects truly were causal, they could still apply to factors other than endocrine-disrupting mycotoxins. After a difficult harvest, grain dust not only contains fungi and mycotoxins, but also organic matter, mites, bacteria, and endotoxins (21). Several of these constituents, including mycotoxins, have immunologic effects $(9,21)$, and these effects could be relevant for reproductive cancer $(6-8)$ and pregnancy outcome (24).

The inferential problem with obscure exposure indicators is partly compensated by the opportunity to investigate several outcomes in the same family cohort, and therefore interpretations of risk patterns are possible for outcomes where common causes might be plausible.

Pregnancy is a strong protective factor for cancer of the breasts, ovaries, and endometrium (6-8). Thus the stronger exposure-cancer associations for parous women of premenopausal age are interesting and could be important from an inferential point of view. The results could be interpreted as hormonal alterations during pregnancy that cause late-term abortion and reduce or eliminate the protective effect of pregnancy on the study cancers. Although mycotoxins (as well as other grain dust constituents) have recognized immunologic and endocrine effects, we are not aware of any single mechanism of action from those constituents that could explain the combined results. The exposure-cancer associations among farmers' daughters were negative, but there were few cases and wide confidence intervals. These results suggest that the same exposure factors that could have an impact among adult farmers were not active in prenatal or early life.

This is the first report of such associations, and further evidence is warranted. There is a need for a better identification, characterization and toxicologic assessment of potential endocrine-disrupting constituents in grain dust and actual exposure data of these constituents in grain handling.

\section{Acknowledgments}

We thank Leif Sundheim at the Norwegian Crop Research Institute for his assessment of the farm exposure data, Aage Johansen at the Cancer Registry, Ole-Henrik
Edland at the Medical Birth Registry of Norway, and Anne Snellingen Bye at Statistics Norway for their file preparation and linking, and Einar Førsund at the Norwegian Crop Research Institute for his electronic preparation of the late blight warning data.

The study received funding from The Research Council of Norway (grant 103542/110).

\section{References}

1. Sharpe RM, Skakkebæk NE. Are oestrogens involved in falling sperm counts and disorders of the male reproductive tract? Lancet 1993;341:1392-5.

2. Golden RJ, Noller KL, Titus-Ernstoff L, Kaufman RH, Mittendorf R, Stillman R, et al. Environmental endocrine modulators and human health: an assessment of the biological evidence. Crit Rev Toxicol 1998;28:109-227.

3. Toppari J, Larsen JC, Christiansen P, Giwercman A, Grandjean $P$, Guilette $L J$, et al. Male reproductive health and environmental xenoestrogens. Environ Health Perspect 1996;104 suppl 4:741-803.

4. Safe SH. Is there an association between exposure to environmental estrogens and breast cancer? Environ Health Perspect 1997;105 suppl 3:675-8.

5. Høyer AP, Grandjean P, Jørgensen T, Brock JW, Hartvig HB. Organochlorine exposure and risk of breast cancer. Lancet 1998;352:1816-20.

6. Kelsey JL. Breast cancer epidemiology: summary and future directions. Epidemiol Rev 1993;15:256-63.

7. Risch HA. Hormonal etiology of epithelial ovarian cancer, with a hypothesis concerning the role of androgens and progesterone. JNCI 1998;90:1774-86.

8. Grady D, Ernster VL. Endometrial cancer. In: Schottenfeld D, Fraumeni JF Jr, editors. Cancer epidemiology and prevention. 2nd ed. New York (NY): Oxford University Press, 1996: $1058-89$

9. Kuiper-Goodman T, Scott PM, Watanabe H. Risk assessment of the mycotoxin zearalenone. Reg Toxicol Pharmacol 1987; $7: 253-306$

10. Sundheim L, Nagayama S, Kawamura O, Tanaka T, Brodal $\mathrm{G}$, Ueno $\mathrm{O}$. Trichothenes and zearalenone in Norwegian barley and wheat. Norw J Agric Sci 1988;2:49-59.

11. Langseth W, Stenwig H, Sogn L, Mo E. Growth of moulds and production of mycotoxins in wheat during drying and storage. Acta Agric Scand, Sect B, Soil Plant Sci 1993; $43: 32-7$

12. Langseth $W$, Elen $O$. The occurrence of deoxynivalenol in Norwegian cereals - differences between years and districts. Acta Agric Scand, Sect B, Soil Plant Sci 1997;47:176-84.

13. Kristensen P, Irgens LM, Andersen A, Bye AS, Sundheim L. Gestational age, birth weight, and perinatal death among births to Norwegian farmers, 1967-1991. Am J Epidemiol 1997;146:329-38.

14. Kristensen P, Andersen A, Irgens LM, Bye AS, Sundheim L. Cancer in offspring of parents engaged in agricultural activities in Norway: incidence and risk factors in the farm environment. Int J Cancer 1996;65:39-50.

15. Kristensen P, Andersen A, Irgens LM, Laake P, Bye AS. Incidence and risk factors of cancer among men and women in Norwegian agriculture. Scand J Work Environ Health 1996; 
22:14-26.

16. Kristensen P, Irgens LM, Andersen A, Bye AS, Sundheim L. Birth defects among offspring of Norwegian farmers, $1967-$ 1991. Epidemiology 1997;8:537-44.

17. Forsund E. Late blight forecasting in Norway 1957-1980. EPPO Bull 1983;13:255-_8.

18. Preston DL, Lubin JH, Pierce DA, McConney ME. Epicure. Seattle (WA): Hirosoft International Corporation, 1993.

19. Langseth $\mathrm{H}$, Andersen $\mathrm{A}$. Cancer incidence among women in the Norwegian pulp and paper industry. Am J Ind Med 1999;36:108-13.

20. Langseth W, Stenwig H, Sogn L, Mo E. Growth of moulds and production of mycotoxins in wheat during drying and storage. Acta Agric Scand, Sect B, Soil Plant Sci 1993; 43:32-7.
21. Lacey J, Dutkiewicz J. Bioaerosols and occupational lung disease. J Aerosol Sci 1994;25:1371— 404.

22. Weidner IS, Møller H, Jensen TK, Skakkebæk NE. Cryptorchidism and hypospadias in sons of gardeners and farmers. Environ Health Perspect 1998;106:793-6.

23. Restrepo M, Muñoz N, Day N, Parra JE, Hernandez C, Bletther $\mathrm{M}$, et al. Birth defects among children born to a population occupationally exposed to pesticides in Colombia. Scand J Work Environ Health 1990;16:239—46.

24. Wegmann TG, Lin H, Guilbert L, Mosmann TR. Bidirectional cytokine interactions in the maternal-fetal relationship: is successful pregnancy a $\mathrm{T}_{\mathrm{H}} 2$ phenomenon? Immunol. Today 1993;14:353-6.

Received for publication: 5 October 1999 